\title{
Retraction Note to: Gingival health in relation to clinical crown length: a case report
}

Alf Volchansky ${ }^{1 *}$ and Peter Cleaton-Jones ${ }^{2}$

\section{Retraction note}

This article [1] has been retracted by the publisher because it was republished in the journal [2] due to an error during transfer of the journal between publishers in 2009. BioMed Central apologizes to the authors and readers for this error and for any inconvenience caused.

\footnotetext{
Author details

'Department of Experimental Odontology and Orthodontics, School of Oral Health Sciences, University of the Witwatersrand, Johannesburg 2050 Wits, South Africa. ${ }^{2}$ Department of Maxillofacial and Oral Surgery, School of Clinical Medicine, University of the Witwatersrand, Johannesburg 2050 Wits, South Africa.
}

\section{References}

1. Volchansky A, Cleaton-Jones P. Gingival health in relation to clinical crown length: a case report. Cases J. 2009;2:9387.

2. Volchansky A, Cleaton-Jones P. Gingival health in relation to clinical crown length: a case report. Cases J. 2009;2:7608.

\footnotetext{
* Correspondence: volchans@iafrica.com

1Department of Experimental Odontology and Orthodontics, School of Oral Health Sciences, University of the Witwatersrand, Johannesburg 2050 Wits, South Africa

Full list of author information is available at the end of the article
} 